\title{
Saúde como matéria de Direito Constitucional no Brasil
}

\author{
Health as a matter of Constitutional Law in Brazil
}

\section{Maria do Carmo Gomes Pinheiro}

Farmacêutica, especialista em Saúde Pública e Vigilância Sanitária, Mestre em Farmacologia Clínica. Especialista em Regulação e Vigilância Sanitária da Agência Nacional de Vigilância Sanitária. Brasília, DF - Brasil.

\section{Luiz Carlos Romero}

Médico, especialista em Saúde Pública e em Direito Sanitário. Pesquisadorcolaborador do Programa de Direito Sanitário da Fundação Oswaldo Cruz. Brasília, DF - Brasil.

Resumo: $O$ estudo analisa os textos constitucionais brasileiros (1824, 1891, 1934, $1937,1946,1967,1988$ ) para recuperar o tratamento que cada um dá a matérias de saúde e ao direito à saúde, contextualizando esse tratamento historicamente e do ponto de vista da evolução do nosso Direito Constitucional. Conclui que o direito à saúde só ganha sede constitucional inconteste em 1988, e revela aspecto inovador do nosso constitucionalismo, representado pela organização institucional, presente já na Constituição de 1934 (que determinava que a União organizasse um serviço nacional de combate a endemias) e na de 1988 (que criou o Sistema Único de Saúde). Por fim, o estudo registra que, ao constitucionalizar o direito à saúde e dar tratamento especial à matéria, o constituinte de 1988 impulsionou o tratamento jurídico da questão da saúde e o desenvolvimento do Direito Sanitário no Brasil.

Palavras chaves: Direito à saúde; Direito Sanitário; Direito Constitucional; Sistema Único de Saúde.

Resumen: El estudio analiza los textos de las constituciones de Brasil (1824, 1891, $1934,1937,1946,1967,1988)$ para recuperar el tratamiento que cada uno da a los temas de salud y al derecho a la salud, y contextualizar este tratamiento históricamente y desde el punto de vista de la evolución del Derecho Constitucional brasileño. Concluye que el derecho a la salud sólo gana lugar constitucional incontestable en 1988, y revela aspecto innovador del constitucionalismo brasileño, representado por la determinación, en el texto constitucional, de la organización institucional del sector, ya presente en la Constitución de 1934 (que determina a la Unión organizar un servicio nacional de lucha contra las enfermedades endémicas) y en la de 1988 (que creó el Sistema Único de Saúde). Al fin, señala que, al constitucionalizar el derecho a la salud y dar tratamiento especial al tema, el constituyente de 1988 impulsó el tratamiento jurídico de la cuestión de la salud y el desarrollo del Derecho Sanitario en Brasil.

Palabras clave: Derecho a la salud; Derecho Sanitario; Derecho Constitucional; Sistema Único de Saúde (Brasil). 
Abstract: The paper analyzes Brazilian constitutions (1824, 1891, 1934, 1937, 1946, 1967 and 1988) to recover the treatment that they give to health matters and to the right to health, historically contextualizing this treatment from the point of view of the evolution of our Constitutional Law. It concludes that the right to health only wins uncontested constitutional seat in 1988, and reveals a novel aspect of our constitutionalism, represented by the institutional organization, already present in the 1934 Constitution (which required the Union to organize a national service to combat endemic diseases) and in that of 1988 (which created the Sistema Único de Saúde). Finally, the paper notes that, when constitucionalizes the right to health and gives special treatment to the subject, the constituent of 1988 spurred the legal treatment of the issue and the development of the Health Law in Brazil.

Keywords: Right to health; Health Law; Constitutional Law; Brazilian Public Health System.

\section{Introdução}

A implementação de ações e serviços públicos de saúde se fez, historicamente, de forma dependente da organização política e social subjacente e da indispensável atuação do Estado nesse campo (seja para defender e proteger a saúde coletiva seja para prover serviços de assistência médica) e, por isso, as políticas de saúde configuram-se, com frequência, como políticas de Estado. Com a criação do Estado Moderno, elas passaram a ter sede constitucional.

É frequente entre os autores contemporâneos brasileiros de textos sobre Saúde Pública e Direito Sanitário a referência ao tratamento inovador e ao destaque que a Constituição Federal de 1988 deu à saúde e ao direito à saúde (Delduque; Oliveira, 2008; Dallari, 2009; Delduque; Marques; Romero, 2009). Para confirmar ou refutar essas afirmações, analisamos os textos constitucionais brasileiros para recuperar o tratamento que cada um dá à matéria - saúde e direito à saúde contextualizando esse tratamento historicamente e do ponto de vista da evolução do nosso Direito Constitucional.

\section{A Carta de 1824 e a primeira constituição republicana de 1891}

A Carta de 1824, outorgada por Pedro I, e a primeira constituição republicana, de 1891, não trazem uma palavra em matéria de saúde. Em verdade, não fazem referência a políticas sociais de nenhuma espécie, com exceção de alguns dispositivos sobre educação. 
O mais próximo que chegam de políticas sociais são: o inciso XXXI do art. 179, que trata dos direitos civis e políticos dos cidadãos brasileiros - que diz que "a Constituição também garante os socorros públicos" (Nogueira, 2001, p. 105); e o $§ 10$ do art. 10 do Ato Adicional de 1834 (Lei no 16, de 12 de agosto de 1834) - que acrescenta, às competências das Assembléias Legislativas Provinciais, "legislar sobre casas de socorros públicos, conventos e quaisquer associações políticas ou religiosas" (Nogueira, 2001, p. 109), ambos da Constituição de 1824 e ausentes na de 1891.

Segundo Borja (1989), a expressão "socorro público" é amplamente conhecida na doutrina do Direito Público que, em geral, não lhe atribui o valor de direito individual, mas o de norma de caráter administrativo, destinada à organização dos serviços públicos. No campo da saúde, consistia na atenção prestada tradicionalmente, em Portugal e no Brasil, pelas santas casas de misericórdia instituições de caridade mantidas como o próprio patrimônio, constituído por doações e legados particulares, e pelo erário - às pessoas incapazes de prover por seus próprios meios a atenção à saúde de que necessitavam para si ou sua família.

Mesmo quando, no Segundo Império, se ampliam os recursos (estabelecimentos de caráter sanitário) para atenção à saúde a que o público poderia ter acesso, "seria temerário incluir o direito à saúde entre os direitos individuais exigíveis ao Estado por via judicial ou administrativa” (Borja, 1989, p. 114).

Essa ausência de matérias de saúde nos textos constitucionais de 1824 e 1891 e nas preocupações do Estado e dos governos, no Império e na República Velha, reflete características do constitucionalismo da época quanto à forma e o conteúdo, mas com uma diferença marcante quanto à origem: enquanto o constitucionalismo moderno deriva de um poder constituinte originário dos povos, nossa constituição de 1824 é uma carta outorgada. Para Ferreira da Cunha, trata-se de uma mistura do princípio monárquico com um fumus de constitucionalismo, e de que [a Carta de 1824] "não é nem uma pura carta constitucional nem uma pura constituição". (Cunha, 2006, p. 280) Para Paulo Bonavides e Paes de Andrade, na introdução de sua História Constitucional do Brasil, "a verdadeira Constituição imperial não estava no texto outorgado, mas no pacto selado entre a monarquia e a escravidão. O Brasil era uma sociedade dividida entre senhores e escravos, sendo o monarca o primeiro desses senhores e o trono, em aliança com a propriedade territorial, a base das 
instituições." (Bonavides; Andrade, 1991, p. 7) Realidade que invalidava toda e qualquer pretensão de um "contrato social".

Ademais, segundo Roemer (1989, p. 17), "ainda que os filósofos e juristas reconheçam desde há muito tempo o direito à atenção à saúde, esse [só] começou a ser contemplado nas constituições e nas leis quando se considerou factível proporcionar certo nível de atenção à saúde". No caso brasileiro, a ausência de responsabilidade e envolvimento do Estado com questões de saúde reflete uma situação que só veio a se modificar no início do século XX: não se dispunha de conhecimento e tecnologia médicos que permitissem a atenção eficaz aos problemas de saúde, quer individuais quer coletivos. "A medicina do século XIX não apresenta soluções muito mais satisfatórias do que a medicina popular" (Figueiredo, 2008, p. 31) e a ausência de políticas, de instituições e de serviços de saúde refletia essa condição de pobreza de meios de intervenção.

Mesmo depois da criação das primeiras escolas de medicina e cirurgia na Bahia e no Rio de Janeiro, após a transferência da Corte Portuguesa para o Rio de Janeiro, eram pouquíssimos os médicos e cirurgiões existentes no país, situação que não se alterou até bem avançado o século XIX.

Com relação às cidades do interior de Minas e, de um modo geral, no Brasil, há unanimidade entre as várias fontes consultadas sobre o número insignificante de médicos em relação à população. A situação se prolonga por todo o século XIX apresentando alguns sinais de mudança a partir de meados do século. (Figueiredo, 2008, p. 70)

Até estar bem avançado o século $\mathrm{XX}$, a assistência à saúde da população, rica ou pobre, era prestada por "um conjunto diversificado de exercentes (físicos, cirurgiões-barbeiros, barbeiros, boticários etc.) e nas Santas Casas de Misericórdia" (Conill, 2003), mas, principalmente, por curandeiros, negros ou indígenas, com intervenção mínima do Estado. As primeiras instituições destinadas aos "socorros públicos" ofereciam mais uma assistência à miséria do que à saúde; eram serviços de caridade e não de assistência médica - limitada que era quanto a seus meios e resultados. A higiene dos ambientes urbanos, a fiscalização do comércio de alimentos e a vistoria de embarcações - em especial na presença ou risco de epidemias, para "evitar a entrada de pestes" - eram atribuições das autoridades municipais, mas dependiam de denúncia, do interesse privado e raramente se faziam de forma permanente e contínua. 
Após a Independência, as responsabilidades relativas à saúde das cidades foram transferidas para as câmaras municipais, reestruturadas pela Constituição de 1824, mantendo-se, no entanto, o padrão de pouca e ou nenhuma atuação do poder local. As questões de higiene passam a ser reguladas por códigos de posturas. (Machado et al., 1978).

É relevante registrar que o artigo da Carta de 1824 - que estabelece a inviolabilidade dos direitos civis e políticos dos cidadãos brasileiros e que têm por base a liberdade, a segurança individual e a propriedade - determina que "nenhum gênero de trabalho, de cultura, indústria ou comércio pode ser proibido, uma vez que não se oponha aos costumes públicos, à segurança e saúde dos cidadãos" (Carta da Lei de 25 de março de 1824, art. 179, XXIV). Há quem veja nesse primor de declaração liberal uma proto-idéia de vigilância sanitária, ao contrário e ainda não cogitada.

A grande epidemia de febre amarela de 1849-50, no entanto, deixou patente a necessidade de rever o papel do Estado e conceder-lhe meios de intervenção. Naquele verão, mais de um terço dos 266 mil habitantes do Rio de Janeiro contraíram febre amarela e o número oficial de mortes, nessa primeira epidemia, chegou a 4.160. No entanto, estudos posteriores estimaram que houve de 10 a 15 mil vítimas fatais (Chalhoub, 1996). Como resposta do governo, foi criada, no ano de 1851, por decreto do Imperador Pedro II, a Junta Central de Higiene Pública, cuja atuação foi absolutamente ineficiente, em razão de sua própria natureza, meramente consultiva, e da insuficiência do conhecimento e da tecnologia médicos disponíveis para o enfrentamento daqueles problemas. Assim sendo, ainda se dispusesse de poder, a Junta não teria - como não teve - meios para agir.

Mas essa institucionalização incipiente não é suficiente, ainda, para estimular a formulação de políticas de Estado de saúde. Ademais, estritamente do ponto de vista do Direito Constitucional, essa classe de matéria era considerada "estranha ao Direito Constitucional" (Polleti, 1999, p. 24).

"Da mesma forma que sua predecessora, a primeira constituição republicana de 24 de fevereiro de 1891 foi liberal pela moderação com que dispôs sobre o relativo à organização social e econômica, em harmonia com o restritivo conceito do papel do Estado então predominante" (Borja, 1989, p. 110). É na nossa primeira constituição republicana que, na opinião de Paulo Bonavides e Pais de Andrade, "o liberalismo 
brasileiro (...) alcança seu ponto mais alto de teorização" (Bonavides; Andrade, 1991, p. 7). Inspirada na Carta norte-americana, não dá conta do surgimento da classe operária como ator social e político e trata de instituir um sistema de poder no qual se sobrepõe, em plenitude, a burguesia. De qualquer forma, inaugura o regime republicano, a forma federativa do Estado e o governo presidencialista - criações do constitucionalismo liberal - sem, no entanto, trazer nenhuma novidade em matéria social, inclusive sem tratar de matérias de saúde em absoluto.

\section{0 ciclo constitucional da Era Vargas - as Constituições de 1934, 1937 e 1946}

As constituições de 1934, 1937 e 1946 fazem parte de um mesmo ciclo histórico e constitucional de renovação institucional do país que conclui pelo estabelecimento, pela via constitucional, de um estado social de direito e do estado de bem estar social. De todos os textos, o de 1934 merece destaque porque, pela primeira vez na história constitucional brasileira, contem matérias referentes à ordem econômica e social e inaugura, com a nova Declaração de Direitos, o Estado social brasileiro.

A Constituição de 1934 reflete o reconhecimento do novo papel que o Estado vinha assumindo em escala planetária, no qual tem uma função ampliada para além do político e do administrativo, reconhecendo-se-lhe a tarefa de intervir nas esferas econômica e social.

A questão social adquiriu uma dimensão incomensurável. Já não é suficiente o Estado Político-administrativo, como não o era o Estado de Direito; agora se espera um Estado de Justiça que sirva ao homem, incluindo a proteção de sua liberdade e de mínima intervenção estatal. (Poletti, 1999, p. 17)

Assim, matérias como saúde, até então consideradas fora do âmbito do Direito Constitucional, passam a ter sede constitucional.

Não escapa ao estudioso da Constituição [de 1934] observar que, entre a pletora de palavras e expressões não-jurídicas e de conteúdo médico-social, floresce um novo conceito de responsabilidade coletiva, social e estatal pela saúde das pessoas e dos grupos sociais e regionais; [...] que marcarão a pauta da vida política brasileira nos decênios seguintes e já não se apagarão das ulteriores constituições de 1937, 1946 e 1967. (Borja, 1989, p. 115)

No Brasil, esse texto constitucional consolida as grandes intervenções da União federal no campo socioeconômico e a incorporação definitiva da política social 
como atribuição do Estado - políticas essas que se iniciam no decênio de 1930 - e inocula uma dose de socialismo no nosso Estado liberal (Bonavides; Andrade, 1991).

Ao caráter reformista da Revolução de Trinta deve ser atribuído a maior e mais substantiva novidade da Constituição de 1934: os títulos sobre a ordem econômica e social. "O novo temário representava para a esfera abstrata das constituições liberais um ponto de mudança considerável, porquanto assinalava já a resolução de estabelecer constitucionalmente no País um estado social de direito" (Bonavides; Andrade, 1991, p. 9). Do ponto de vista material, a Constituição de 34 introduz o que, na opinião de Bonavides e Andrade, constitui "matéria nova e surpreendentemente inédita ao constitucionalismo pátrio: as disposições sobre família, educação, ordem econômica e social, segurança nacional e justiça eleitoral” (Bonavides; Andrade, 1991, p. 287).

É importante notar que, no âmbito dos novos direitos sociais, a saúde tem menor relevância quando comparada aos demais: enquanto o trabalho, a educação, as artes, as letras e a cultura são objeto de favorecimento, amparo e estímulo do Estado, a saúde continua a ser concebida com indisfarçável parcialidade e na perspectiva de benefício, outorga.

Cuidar da saúde e da assistência públicas passa a ser competência concorrente da União e dos estados (art. 10, II). O "amparo à maternidade e à infância"; a adoção de "medidas legislativas e administrativas tendentes a restringir a mortalidade e a morbidade infantis, e de higiene social, que impeçam a propagação de doenças transmissíveis"; e "cuidar da higiene mental e incentivar a luta contra os venenos sociais" são incumbidas pela Carta de 1934 à União, aos estados e aos municípios (art. 138, c, f, g). A Constituição determina que a proteção social do trabalhador seja promovida e, no seu âmbito, a legislação do trabalho disporá sobre a assistência médica e sanitária ao trabalhador e à gestante (art. 121 , caput e $\S 1^{\circ}, h$ ).

Por fim, determina que "a União organizará o serviço nacional de combate às grandes endemias do País, cabendo-Ihe o custeio, a direção técnica e administrativa nas zonas onde a execução do mesmo exceder as possibilidades dos governos locais" (art. 140), e torna "obrigatório, em todo o território nacional, o amparo à maternidade e à infância, para o que a União, os estados e os municípios destinarão um por cento das respectivas rendas tributárias" (art. 141). Inaugura, assim, uma política de vinculação de recursos tributários para o financiamento de ações e 
serviços públicos de saúde, com sede constitucional, que se manteria polêmica e atual até hoje.

Em matéria de saúde, assim, a grande novidade trazida pelo texto da Constituição de 1934 é a introdução enviesada do direito à saúde. Direito, no entanto, que ainda não é um direito individual nem, mesmo, social, mas corporativo: a garantia das prestações a ele associadas é dada apenas a quem faz parte de uma relação laboral. Os cidadãos brasileiros, como tais, não estão autorizados constitucionalmente a exigir do Estado esse direito e, tampouco, o Estado está obrigado a responder seja pela atenção à saúde individual, seja aos problemas de saúde coletiva.

Célio Borja (1989) tem opinião distinta. Para ele, com a Constituição de 1934 a proteção e a atenção à saúde se convertem em direito do trabalhador, exigíveis ao empregador e ao sistema de previdência social organizado nesse período. Cristina Fonseca (2007), no entanto, vê a questão de outra perspectiva: para ela, a constituição de dois formatos de prestação de serviços de saúde está associada a duas formas diversas de inclusão social. No âmbito da previdência social, a assistência médica era um direito assegurado pela legislação trabalhista a determinadas categorias de trabalhadores e deveria ser garantida pelo Estado, pelos empregadores e pelos empregados; já no âmbito da saúde pública, o acesso aos serviços não constituía um direito social adquirido, mas um benefício concedido pelo Estado e, portanto, não se formalizou uma obrigação ou dever do Estado para com o cidadão.

De qualquer forma, "aquele bem coletivo por natureza [saúde] não seria percebido e interpretado como um direito, como ocorre nos contextos democráticos, mas como outorga de um poder benevolente que, discricionariamente, decide como provê-lo" (Fonseca, 2007, p. 10). Opinião que também é defendida por Bonavides e Andrade, segundo os quais "a ditadura do Estado Novo criou o mito de que as conquistas, como a legislação, por exemplo, não significavam conquistas, mas dádivas do poder e do seu chefe" (Bonavides; Andrade, p. 410).

A Constituição de 1937 - conhecida como "a Polaca" por, de forma similar à da Polônia, incorporar elementos autoritários em voga no constitucionalismo europeu da época - pouco altera a forma como as matérias de saúde estavam tratadas no texto de 1934, dando-Ihes, no entanto, nova formatação. Ela é, no entanto, a base do 
surgimento e desenvolvimento de uma burocracia estatal e de um Poder Executivo Federal forte e concentrador e de um Poder Legislativo fraco, fato que terá importância duradora no que diz respeito ao direito à saúde e na organização da atenção à saúde em nosso país.

A Constituição de 1937 dá à União competência privativa para legislar sobre "normas fundamentais da defesa e proteção da saúde, especialmente da saúde da criança" (art. 16, XXVII). Permite aos estados legislar apenas sobre assistência pública, obras de higiene popular, casas de saúde, clínicas, estações de clima e fontes medicinais, no caso de haver lei federal sobre a matéria, para suprir-lhe as deficiências ou atender às peculiaridades locais, desde que não dispensem ou diminuam as exigências de lei federal; em não havendo lei federal, até que esta os regule $($ art. 18, c). Aos municípios é assegurada autonomia "em tudo quanto respeite ao seu peculiar interesse e, especialmente, à organização dos serviços públicos de caráter local" (art. 26, c).

A infância e a juventude mantêm-se como "objeto de cuidados e garantias especiais por parte do Estado, que tomará todas as medidas destinadas a assegurarIhes condições físicas e morais de vida sã e de harmonioso desenvolvimento das suas faculdades" (art. 27), e a legislação do trabalho "observará assistência médica e higiênica ao trabalhador e à gestante", instituindo a licença maternidade (art. 137, l) .

A Constituinte de 1946 resultou de um movimento nacional contra o Estado Novo e a constituição que dele emergiu incluiu avanços e recuos, mas em nada alterou a situação do estado social de direito implantado. Bonavides e Andrade (1991, p. 412) defendem que "a Constituição de 1946 assegurava um Estado social de direito vazado na mais ampla tradição liberal dos juristas brasileiros". Do ponto de vista dos direitos sociais, no entanto, os textos de 1937 e 1946 são bem mais moderados do que o de 1934.

Como novidade, a Constituição de 1946 traz uma ampliação dos direitos sociais relacionados ao trabalho e à previdência social - e, nesse âmbito, à assistência médica. Mantém a competência da União para legislar sobre "normas gerais de proteção e defesa da saúde" (art. 5o $\mathrm{XV}$, b) e a "legislação estadual supletiva ou complementar" (art. 6ํำ. Institui os "preceitos" de higiene e segurança do trabalho e de assistência sanitária, inclusive hospitalar e médica preventiva, ao trabalhador e à gestante, no âmbito da legislação do trabalho e da previdência social 
(art. 157, VIII e XIV), e obriga a assistência à maternidade, à infância e à adolescência (art. 164). Por fim, isenta do imposto de consumo os artigos que a lei classificar como o mínimo indispensável a tratamento médico das pessoas de restrita capacidade econômica (art. $15 \S 1^{\circ}$ ).

Ainda que as matérias de saúde - e, em especial, o direito à saúde como direito social - tenha pequena expressão nos textos constitucionais da Era Vargas, o contexto político-institucional criado pelas cartas de 1934, 1937 e 1946 teve reflexos profundos e duradouros nas políticas públicas de saúde e na organização do setor. O tratamento dado às questões de saúde no texto constitucional de 1934 - a higiene do trabalho e a assistência médica como decorrentes da relação de trabalho e, depois, do âmbito da legislação do trabalho e previdenciária; e as demais ações para "defesa e proteção da saúde" em outro âmbito legal e institucional - conformaram de forma permanente a formulação das políticas, a organização e a gestão dos serviços de saúde.

Para Cristina Fonseca (2007, p. 18-19), "o processo de constituição de políticas públicas de saúde no Brasil, a partir dos anos 1930, instituiu dois formatos diferenciados de prestação de serviços de saúde, conformados através da criação de dois ministérios: o do Trabalho, Indústria e Comércio (MTIC) e o da Educação e Saúde Pública (MESP). A distinção entre essas duas áreas caracterizou duas formas distintas de política social, uma corporativa e outra universalista, que correspondiam à configuração de grupos de interesses também diversos".

Com respeito à sua dimensão institucional, as ações públicas de saúde acompanhariam as distinções estabelecidas entre o MTIC e o MESP. Muito além de uma simples divisão e demarcação de funções segundo a área de atuação de cada órgão, a separação definiu, naquele contexto de fundação e estruturação de políticas sociais, modelos diferenciados de reconhecimento de direitos sociais. De um lado se consolidaria a assistência médica individual previdenciária implementada pelo MTIC, a qual, com o passar dos anos, tornou-se uma das principais referências para a prestação dos serviços públicos de saúde voltados para os indivíduos reconhecidos como cidadãos, ou seja, para aqueles inseridos no mercado de trabalho e amparados por princípios corporativos. De outro lado, no MESP, atrelada à educação, seria estruturada a saúde pública, ou melhor, tudo que dissesse respeito à saúde da população e que não se encontrava na área de abrangência da medicina previdenciária. A esse ministério caberia a prestação de serviços aos identificados como pré-cidadãos: os pobres, os desempregados, os que exerciam atividades informais; 
em outras palavras, todos os inabilitados a usufruir os serviços oferecidos pelos órgãos previdenciários. (Fonseca, 2007, p. 41-42)

Esse entendimento e essa conformação institucional - que decorrem dos textos constitucionais de 1934, 1937 e 1946 - só vieram a ser reformados no texto da Constituição de 1988.

Outra característica importante conferida ao Estado brasileiro pelas constituições da Era Vargas foi a implementação de um Estado centralizado, a inviabilização de um pacto federativo e o reforço do Poder Executivo. Essas características se transferiram - como não poderia deixar de ser - para a formulação de uma política de saúde centralizadora, definida a partir do governo federal, responsável pela redução da responsabilidade de estados e municípios para com ela.

A incapacidade para a construção de um pacto federativo para a formulação e, principalmente, a implementação de ações e serviços públicos de saúde que decorre dos textos constitucionais e da política da Era Vargas é devida à indefinição das instâncias responsáveis por assegurar prestacionalmente o direito à saúde. No caso da assistência médica, o papel da União como financiadora e prestadora de serviços de previdência estava claro, mas o mesmo, no entanto, não aconteceu em relação ao papel que caberia a cada um dos entes da Federação quanto à prestação dos demais serviços de saúde à população, em caráter universal.

Por outro lado, ao consagrar o Estado como o principal prestador de ações e serviços públicos de saúde, permitiu organizar e profissionalizar a burocracia do setor e desenvolver uma ampla e complexa rede de serviços públicos de saúde que constituíram o arcabouço institucional da saúde pública em âmbito nacional.

As constituições de 1934 e 1937 criaram as condições para, por um lado, a consolidação da assistência médica previdenciária e, por outro, a implementação de uma política social de saúde de caráter universal, com base na centralização, burocratização e ampla presença do governo federal nos estados e municípios.

\section{Saúde e ditadura - a Constituição de 1967}

A Constituição de 1967 objetivou a institucionalização do golpe militar de 1964 e, dessa forma, caracterizou-se pela centralização do poder político e pelo reforço do Poder Executivo, sobrepondo-o aos Poderes Legislativo e Judiciário. Manteve formalmente os mesmos direitos e garantias individuais presentes na Constituição de 
1946, mas, na prática, contestou o texto adotado ao transferir para a lei ordinária o estabelecimento dos termos em que se exerceriam aqueles direitos.

A carta de 1967 vem para permitir a consolidação do modelo capitalista de Estado que instalou, nos países capitalistas periféricos como o nosso, governos burocrático-autoritários com objetivo de reorganização social e racionalização administrativa com vistas à abertura da economia ao capital financeiro e às empresas multinacionais e levou à desnacionalização da economia. Esses governos promoveram reorganização administrativa que concentrou as decisões no Poder Executivo e reprimiu violentamente a organização e participação dos trabalhadores, ao mesmo tempo em que promovia a retração dos salários.

Do ponto de vista ideológico, "textos formalmente liberais colidiam com a realidade ditatorial e vários dispositivos autoritários" (Bonavides, Andrade, 1991, p. 441-442). Do ponto de vista material, segue o padrão das constituições do pósguerra, contendo normas relativas à ordem social e econômica, em sua maioria de natureza programática. Além disso, em seus 210 artigos, se adotam disposições sobre matérias que, nos sistemas normativos clássicos, são objeto de leis ordinárias e de regulamentos administrativos (Borja, 1989, p. 111).

Entre 1969 e 1985, o texto de 1967 foi objeto de 27 emendas constitucionais. No entanto, nenhum dos dispositivos que tratam de matéria de saúde foi alterado por elas (Emendas Constitucionais, 1999).

Em matéria de saúde, concentrou na União a competência para "estabelecer e executar planos nacionais de saúde" (art. 8ํ, XVII, c) e para legislar sobre "normas gerais de defesa e proteção da saúde", mantendo, no entanto, a competência dos estados para legislar supletivamente sobre essa matéria (art. 8ํㅡ, XIV e parágrafo único).

Como a Constituição de 1934, a de 1967 assegura aos trabalhadores o direito à higiene e segurança do trabalho; à assistência sanitária, hospitalar e médica preventiva; e a colônias de férias e clínicas de repouso, recuperação e convalescença, mantidas pela União (art. 165 incisos IX, XV e XVIII). A família permanece objeto de proteção especial dos Poderes Públicos (art. 175), bem como a assistência à maternidade, à infância e à adolescência. Aos ex-combatentes da Segunda Guerra Mundial, que tenham participado efetivamente em operações bélicas 
da Força Expedicionária, é assegurado o direito à assistência médica e hospitalar, se carentes de recursos (art. 197, d).

A concentração política, legislativa, normativa e do financiamento das ações e serviços públicos de saúde nas competências da União que esse arcabouço jurídico institui permitiu a expansão da assistência médica da previdência social, em especial durante a década de 1970, e levou à instituição do Sistema Nacional de Saúde, em 1975, consolidando a existência de dois sistemas de saúde paralelos e incomunicáveis.

A instituição do Sistema Nacional de Saúde objetivou compatibilizar e organizar - ainda que não definisse a coordenação central do Sistema - as ações de saúde cuja responsabilidade encontrava-se dispersa por vários órgãos federais (ministérios da Saúde, da Previdência, da Educação, do Trabalho e militares, Presidência da República e outros). Entre outras coisas, ela manteve o paradigma dominante, mantendo separadas as ações de saúde coletiva - cuja gestão foi atribuída ao Ministério da Saúde - das ações voltadas para a assistência médica individual - geridas pelo Ministério da Previdência.

No âmbito da Previdência Social, a assistência médica passou a ter prioridade sobre os benefícios pecuniários e transformou-se no principal fator de barganha clientelística da política de favores que se estabeleceu. Em decorrência, os gastos do Estado com previdência cresceram substancialmente a partir da década de 1960, levando a uma crise de insolvência do setor em pouco mais de uma década. Sem nenhuma participação dos trabalhadores, adotou-se uma política de ampliação desses benefícios, com base na compra de serviços ao setor privado de saúde, e no financiamento, de forma subsidiada pelo Estado, da construção e ampliação hospitais e clínicas privadas - o que permitiu a rápida e importante expansão, capitalização e desenvolvimento tecnológico do empresariado e dos serviços privados de saúde.

O Ministério da Saúde também foi reorganizado e re-aparelhado, disso resultando a criação e reestruturação dos órgãos voltados para o controle de endemias, educação sanitária, epidemiologia e estatística da saúde e organização sanitária. A conformação do atual Sistema Nacional de Vigilância Sanitária e a organização das ações de vigilância epidemiológica e do Programa Nacional de Imunizações é, também, dessa época. 
A Previdência Social passou a ter poder hegemônico e centralizador sobre o setor saúde, na qualidade de grande financiador da assistência médica. A centralização de recursos no nível federal durante o período autoritário - em especial após a reforma tributária de 1967 - e o crescimento da oferta de serviços de assistência médica pela Previdência Social tiveram, como consequência, a redução da participação de estados e municípios no investimento, no financiamento e na própria execução de ações e serviços de saúde (Romero, 2008).

... transformou a Previdência Social no grande comprador e financiador de serviços médicos da rede privada, com a implementação de um modelo assistencial caracterizado pela tecnificação dos atos médicos, pela ênfase na assistência hospitalar e pelo assalariamento dos profissionais de saúde. As ações de saúde coletiva, por outro lado, foram abandonadas à míngua dos parcos recursos com que era dotado o Ministério da Saúde. (Romero, 2008, p. 74)

O agravamento das condições de vida e de saúde da população brasileira, a crise da Previdência, a crítica à irracionalidade das políticas e da organização do setor de saúde favoreceram a experimentação, a partir de meados da década de 1970 e, principalmente, durante toda a década de 1980, de alternativas de integração institucional, no nível federal, enquanto, no nível municipal (Montes Claros, Niterói, Campinas, Londrina), demonstrava-se a viabilidade da implantação de um modelo eficiente de sistema unificado de saúde com gestão municipal.

O processo teve como liderança intelectual e política o autodenominado Movimento Sanitário, composto por um grupo de intelectuais, médicos e lideranças políticas do setor saúde, que teve um papel destacado na oposição ao regime militar. Contou também com a participação dos movimentos populares em saúde que proliferaram na década de 1970 , originados nos bairros pobres das periferias das grandes cidades, caracterizados pela reivindicação de melhores condições de saneamento, assistência médica, transportes.

O Movimento Sanitário representou um pensamento contra-hegemônico, contrapondo-se ao comando político e financeiro do sistema previdenciário, caracterizado pela aliança entre os interesses empresariais privados de saúde e a burocracia estatal, e construiu as bases teóricas e políticas do reconhecimento da saúde como direito fundamental e das proposições de reorganização do setor que foram levadas e adotadas pela Assembléia Constituinte de 1987-88. 


\section{A Constituição Cidadã de 1988}

A Assembléia Constituinte de 1987-88 é o resultado de um movimento que envolveu todos os segmentos da Nação, "profundamente rebelada contra o mais longo eclipse das liberdades públicas" (Bonavides; Andrade, 1991, p. 451), em prol da redemocratização do País e da re-instituição do Estado Social de Direito. Ao mesmo tempo em que os brasileiros "enfrentavam a ditadura e denunciavam o autoritarismo impregnado nas instituições e nas práticas de saúde, defendiam a democratização da saúde como parte da democratização da vida social, do Estado e dos seus aparelhos" (Paim, 2009, p. 29).

Materialmente, a produção constituinte foi caudalosa: um texto de 245 artigos mais 70 outros de disposições transitórias.

Em matéria de saúde, a Assembléia Constituinte promoveu e institucionalizou, com o texto que elaborou, uma reforma sanitária radical e uma mudança de paradigma: a saúde passou a ser um direito fundamental, universal, a ser assegurado pelo Estado; as ações e serviços de saúde são declaradas de relevância pública; as assistências médica e farmacêutica deixaram de ser entendidas como benefícios de previdência e passaram a ser tratadas como ações de saúde; os serviços e sistemas públicos de saúde foram unificados conferindo-Ihes direção única em cada esfera de governo.

A reforma sanitária que se consolida com o texto de 1988, fundada no direito universal à saúde e na realização de profundas mudanças políticas e organizacionais do setor, se faz na perspectiva de que a transição democrática traria justiça social, além de crescimento econômico. Na opinião de Sílvia Gerschman (2004, p. 21), a própria proposta de reforma sanitária somente se tornou viável no contexto da transição democrática, já que "implica em profundas transformações na concepção dos direitos de cidadania e na atuação política do governo, de modo a possibilitar o exercício desses direitos".

A adoção dessa nova política de Estado está, dessa forma, imbricada, por um lado, ao processo de redemocratização do País e às mudanças na esfera do Estado e das relações do Estado com a sociedade, e, por outro, à maneira pela qual os diversos interesses que compuseram o movimento social em saúde lidaram entre si e se fizeram representar nas instâncias institucionais da política de saúde (Gerschman, 
2004). A viabilização política das teses da reforma no âmbito do processo constituinte foi possível porque os representantes do movimento buscaram o envolvimento de políticos, partidos e autoridades institucionais (Campos, 2009).

Três grandes campos de interesses se organizaram na Assembléia Nacional Constituinte de 1987-88, no que diz respeito à saúde: a "coalizão reformista", que resultou da aliança entre os movimentos sanitário, sindical e popular e os parlamentares "progressistas" - que defendia as propostas da 8 $8^{\text {a }}$ Conferência Nacional de Saúde, de 1986; o forte lobby orquestrado pelo setor privado dependente do Estado, isto é, prestador de serviços ao setor público, aliado aos parlamentares dos partidos mais conservadores - que defendia a livre iniciativa da produção de bens e serviços de saúde e o relaxamento dos mecanismos de regulação estatal, contrários à universalização; e os aliados do sistema privado de atenção médica supletiva, constituído de setores autônomos do empresariado médico que não dependia da venda de serviços ao Estado - frequentemente aliado do segundo grupo e que defendia a total autonomia do setor, sem qualquer forma de regulação estatal (Gomes, 1996).

Um texto de 1989 sintetiza as características desse projeto de reforma da saúde que foi transferido para o texto constitucional:

A noção de Reforma Sanitária contém um projeto que é, simultaneamente, técnico e político, de intervenção positiva na configuração assumida pela problemática da saúde na sociedade brasileira contemporânea e são seus fundamentos principais: um conceito abrangente de saúde, que a toma como resultante das condições de vida e de trabalho prevalecentes na nossa sociedade, $e$ do padrão de organização da base estruturada de serviços de saúde, voltados ao indivíduo, às coletividades e ao meio ambiente. (Marques, 1989, p. 14)

O destaque dado à saúde no novo texto constitucional - tratada em uma sessão própria - reflete não apenas a ampliação das tarefas atribuídas ao Estado nesse campo, mas, também, a relevância de que passaram a se revestir para o povo brasileiro, naquele contexto histórico, as questões de saúde e, por último, mas não menos importante, a atuação de uma liderança intelectual e política, forjada no âmbito do setor saúde, da universidade e dos movimentos sociais.

Sílvia Gershman (2004), em seu estudo sobre a reforma sanitária brasileira, defende a opinião de que os atores sociais favoráveis à reforma interagiram em um 
campo não conflitivo, enquanto a diversidade de interesses que caracterizava seus variados segmentos estava diluída na oposição em bloco ao regime autoritário e às políticas de saúde predominantes nos anos finais da ditadura e - acrescentaríamos aos interesses que se opunham à reforma, imediatamente antes e durante o processo constituinte. Segundo Gastão Wagner Campos, o movimento pela reforma sanitária conseguiu elaborar um programa comum "apesar da variedade da origem, dos interesses e das escolas de pensamento de seus membros" (Campos, 2009, p. 52).

"Uma das mudanças centrais da Constituição de 1988 foi retirar o direito à saúde da esfera trabalhista e do mercado e submetê-lo à esfera do direito de cidadania" (Silva, 2009, p. 41). O direito à saúde, instituído desde 1934 como ampliação do direito ao trabalho - portanto um direito apenas dos trabalhadores, não de todos os cidadãos - torna-se, para além do direito à higiene e segurança do trabalho e à assistência médica, um direito social, elencado ao lado do direito à educação, ao trabalho, à moradia, ao lazer, à segurança, à previdência social, à proteção à maternidade e à infância e à assistência aos desamparados (art. 6o).

Definir expressamente, em sede constitucional, a saúde como um direito humano fundamental significou um avanço enorme para a proteção da saúde em nosso País, uma vez que ela passou a ser protegida juridicamente e uma série de obrigações foi estabelecida para os agentes públicos para a plena realização daquele direito (Aith, 2007). Nesse contexto, foi conferido ao Estado o dever de garantir a efetivação do direito à saúde, mediante políticas sociais e econômicas que visem à redução do risco de doença e ao acesso universal e igualitário às ações e serviços para a promoção, proteção e recuperação da saúde.

Na opinião de Nelson Rodrigues dos Santos (2009, p. 19), em decorrência dessa nova política de Estado que se inaugura com a Constituição de 1988, o Sistema Único de Saúde transformou-se no maior projeto público de inclusão social em menos de duas décadas, a vista dos grandes números de atendimentos realizados, dos resultados de programas exitosos de controle de doenças e da "explosiva inclusão de aproximadamente metade da população, antes excluída".

Ao declarar que as ações e serviços de saúde são de relevância pública (art. 197), a Constituição de 1988 atribui competência ao poder público para dispor sobre sua regulamentação, execução e fiscalização. 
Ainda que a criação de instituições ou organismos responsáveis pela implementação de determinações de natureza programática não seja uma absoluta novidade no nosso constitucionalismo - a Constituição de 1934 determinava (art. 140) que a União organizasse o serviço nacional de combate às grandes endemias -, a Constituição de 1988 faz isso de uma forma que não apenas é nova como surpreendente em termos de matéria constitucional. A Carta de 1988 não apenas cria - enquanto a Constituição de 1934 mandava que a União "organizasse" - uma instituição para organizar e executar ações e serviços públicos de saúde, como determina os princípios, as diretrizes e a forma dessa organização (art. 198).

Com a Constituição de 1988, o Sistema Único de Saúde (SUS) por ela criado torna-se a instituição jurídica mais importante do Direito Sanitário. E essa instituição já nasce com suas características estruturais e as diretrizes para sua organização (art. 198 caput e incisos I a III); competências (art. 200); parâmetros de financiamento (art. 198 §§ $1^{\circ}$ a $3^{\circ}$ ) e atuação dos agentes públicos estatais em relação a ela (arts. 196, 197 e 198) definidos no texto da constituição. Como opção política, o SUS traz o que Gastão Wagner Campos (2009, p. 50) denomina "marca genética do intervencionismo estatal sobre a dinâmica de mercado", "primo irmão dos sistemas socializados de saúde e sobrinho do estado de bem estar social” - e, por isso, já nasce anacrônico, num "tempo áureo do neoliberalismo".

É interessante notar que o SUS foi criado em plena crise do socialismo e das políticas de bem-estar social e sua implementação se fez numa época de retomada do liberalismo - o que Campos chama de "sanha privatizante dos últimos vinte anos" (Campos, 2009, p. 54).

Outro aspecto igualmente significativo para a análise da questão da saúde como matéria constitucional é o fato de que a nova Constituição, como resultado da ação política dos movimentos sociais no processo constituinte e por reflexo de questões conjunturais - a Assembléia Constituinte recebeu 122 emendas populares, algumas das quais com mais de um milhão de assinaturas, e foi registrada a presença diária de cerca de dez mil pessoas nas dependências do Congresso Nacional durante os trabalhos constituintes (Bonavides; Andrade, 1991, p. 470), passou a dar acolhida a matérias tradicionalmente não contempladas em textos constitucionais: a regulamentação da doação e transplante de órgãos, da doação e 
transfusão de sangue (art. $199 \S 4^{\circ}$ ) e da propaganda comercial de tabaco, bebidas alcoólicas, agrotóxicos, medicamentos e terapias (art. $220 \S 4^{\circ}$ ).

Esse fato é mais um indicador de como a materialidade das constituições corresponde mais a contextos históricos e políticos - inclusive no âmbito de políticas setoriais, como é o caso da saúde - do que a princípios jurídicos.

A Assembléia Constituinte de 1987-88 foi um divisor de águas na institucionalização da saúde no Brasil: transformou em dispositivo constitucional o direito à saúde, tornou as ações e serviços de saúde de relevância pública e instituiu um sistema público de saúde, de cobertura universal, organizado segundo diretrizes de unificação das diversas instituições do setor, descentralização, atendimento integral e participação da comunidade. Ademais, ao constitucionalizar a saúde, deu o impulso que faltava para o desenvolvimento de um Direito Sanitário, disciplina até então pouco desenvolvida no País (Romero, 2008, p. 73).

Esse fato, a consolidação do Direito Sanitário como ramo jurídico, é a última, mas não menos importante, das consequências do tratamento dado à saúde pela Constituição de 1988.

Para Fernando Aith (2007, p. 83-84), foi somente a partir da Constituição de 1988 que o Direito Sanitário consolidou-se definitivamente no País, quando "adquiriu conteúdo suficientemente sólido para que se possa compreendê-lo de forma autônoma", ainda que possua intrinsecamente interfaces com os outros campos da ciência jurídica. O tratamento especial que a Constituição deu ao tema foi responsável pela produção de "uma verdadeira rede normativa voltada exclusivamente para o tratamento jurídico da questão da saúde no Brasil”.

Não seria possível concluir sem ao menos comentar que as esperanças de construir um sistema de saúde único, de cobertura universal e capaz de efetivar o direito à saúde se frustraram em grande parte nesses vinte anos que se seguiram à promulgação da Constituição Cidadã. A política de saúde que ela inaugura - mais do que qualquer outra política social - teve, nesse período, na opinião de Gershman (2004, p. 15), "um cenário de implementação profundamente adverso" com a adoção de políticas de orientação neoliberal.

As mudanças ocorridas levaram à perda do caráter universal do sistema de saúde e ao desinvestimento em recursos humanos, instalações, equipamentos e preservação do parque hospitalar do País, ao mesmo tempo em que se estimulava o 
crescimento dos planos privados de assistência médica entre as classes médias e trabalhadoras.

Mas essa é outra história.

\section{Conclusão}

Apesar do debate entre "restritivistas" e "extensivistas" sobre a composição e a materialidade dos textos constitucionais, não se firmou nenhuma teoria ou doutrina que determinasse quais matérias são próprias às constituições e quais não. O que decide a materialidade dos textos constitucionais são, mais do que os fatores técnicojurídicos, os fatores políticos, a configuração do poder e o momento histórico. As constituições constituem, assim, textos tanto jurídicos como políticos.

Nesse sentido, as constituições formuladas sob o influxo do liberalismo político de meados do século XIX - como as nossas cartas de 1824 e 1891 - cuidavam apenas de estabelecer a organização dos poderes e os direitos civis e políticos do cidadão; já as constituições elaboradas ao final do século XX - como a Constituição de 1988 -, que traduzem contextos favoráveis à intervenção do Estado nos domínios econômico e social, têm textos ampliados, que acrescentam, aos dois temas do constitucionalismo clássico, disposições sobre matéria administrativa e judiciária e de regulação da atividade econômica e social, entre outras.

A saúde passa a ser matéria constitucional quando as tarefas do Estado se ampliam para dar efetivação aos direitos sociais fundamentais e, no seu âmbito, o reconhecimento do direito à saúde como um deles ou, pelo menos, como uma tarefa do Estado.

Ademais, a abordagem restritiva quanto à matéria, dos textos constitucionais de orientação liberal, não é uma opção meramente técnica ou doutrinária, mas principalmente ideológica - e o fato de eles não tratarem de matérias de saúde e, em especial, de não reconhecerem o direito à saúde como direito humano é demonstrativo disso. Ao conceber a atenção à saúde apenas como uma das muitas necessidades do indivíduo e a produção e o consumo de ações e serviços de saúde como uma questão de mercado e não uma tarefa do Estado, as constituições liberais não têm espaço para o direito à saúde como direito fundamental nem para a explicitação das tarefas do Estado em relação a ele. 
Além disso, um fator externo ao Direito Constitucional, mas relevante para o esclarecimento dessa questão do tratamento constitucional de matérias de saúde, é o estágio de desenvolvimento científico e tecnológico em saúde dos diferentes momentos históricos em que se formulam as constituições. É o conhecimento médico e o desenvolvimento de tecnologias de saúde que possibilitam a capacidade de intervenção - seja dos particulares, seja do Estado - sobre a saúde dos indivíduos e as condições da saúde coletiva. São eles que permitem materializar políticas públicas de saúde, a criação de serviços e a execução de programas. Dessa forma, só após o advento da medicina científica no início do século XX acumulam-se conhecimentos e tecnologias biomédicos suficientes para tornar factível proporcionar ações e serviços de saúde com um mínimo de efetividade. Até então, ainda que o Estado dispusesse de poder para intervir em problemas de saúde, não teria meios para agir - seus recursos alcançavam pouco mais do que o necessário para "organizar os socorros públicos" - e, sem meios com que materializá-lo, seria muito difícil que as cartas de então incluíssem o direito à saúde entre os direitos individuais exigíveis ao Estado.

O direito à saúde, e outros direitos sociais, só passa a ser contemplado, ao lado dos já presentes e conhecidos "direitos civis" e "direitos políticos", nos textos das constituições dos novos governos republicanos dos estados nacionais que emergiram nos anos finais da Primeira Guerra.

No Brasil, a tese de que a Constituição de 1988, ao reconhecer a saúde como um direito fundamental, deu tratamento inovador à saúde no âmbito do constitucionalismo pátrio procede: matérias de saúde inexistem ou são marginais nos textos de nossas constituições anteriores. A instituição do direito à higiene no trabalho e à assistência médica conferido aos trabalhadores formais a partir do texto de 1934 (e mantido nos demais, anteriores a 1988) pode ser visto como os primórdios do reconhecimento ao direito à saúde e do papel do Estado com sua efetivação. No entanto, não é consensual que ela represente, já então, o reconhecimento de um direito fundamental.

Se para Célio Borja (1989), com a Constituição de 1934, a proteção e a atenção à saúde se convertem em direito do trabalhador, exigível ao empregador e ao sistema de previdência social organizado nesse período. Para Cristina Fonseca (2007), no entanto, o que constituía um direito assegurado era a assistência médica, e apenas a determinadas categorias de trabalhadores, no âmbito da previdência 
social. Já no âmbito da saúde coletiva, o acesso a ações e serviços não constituía um direito social adquirido, mas um benefício concedido pelo Estado e, portanto, não se formalizou uma obrigação ou dever do Estado para com o cidadão. Bonavides e Andrade (1991), para quem essas não eram conquistas, mas dádivas do poder, defendem opinião semelhante.

Em nosso entendimento, trata-se de uma introdução enviesada do direito à saúde que se faz na ótica da ampliação do direito ao trabalho - ainda assim não universalizado - e que, quando se materializa como política de governo, se faz sob a égide do mercado, da compra de serviços à iniciativa privada pelo Estado, e não pela estruturação de um sistema estatal de ações e serviços de saúde.

A novidade introduzida pelo texto de 1934, e que se manteria nas constituições posteriores, não é, ainda, um direito individual nem, mesmo, social, mas corporativo: a garantia das prestações associadas e esse direito é dada apenas a quem faz parte de uma relação laboral. O cidadão brasileiro como tal não está autorizado constitucionalmente a exigir do Estado esse direito e, tampouco, o Estado está obrigado a responder seja pela atenção à saúde individual seja aos problemas de saúde coletiva, ainda que a Constituição determine que se aparelhe para tanto. Ainda não são direitos subjetivos; são benefícios, outorga. Em nosso constitucionalismo, o direito à saúde só ganha sede constitucional inconteste em 1988.

Um aspecto inédito no nosso constitucionalismo é a organização institucional, presente na Constituição de 1934 e que retornou na de 1988 de forma absolutamente inovadora em termos do tratamento dado à matéria em um texto constitucional: em 1934, a Constituição determinava que a União organizasse o serviço nacional de combate às grandes endemias; em 1988, criou o Sistema Único de Saúde.

Matérias dessa natureza - a criação das instituições que concretizarão os direitos sociais - não são típicas de textos constitucionais. Nos dois casos brasileiros, sua inclusão revela, a nosso ver, a relevância que o constituinte reconhece aos problemas de saúde, naquelas conjunturas específicas, e à tarefa que pretende atribuir ao Estado em relação a eles. Não por outra razão, as ações e serviços de saúde são definidos como de relevância pública, no texto de 1988.

O aspecto inovador de 1988 quanto a isso está em que, mais do que instituir o sistema de saúde, o texto constitucional define suas características estruturais e as 
diretrizes para sua organização; e estabelece suas competências e os parâmetros para o seu funcionamento, além da atuação dos agentes públicos estatais em seu âmbito.

Por fim, há que registrar que, ao constitucionalizar a saúde e dar-lhe tratamento especial, o constituinte de 1988 impulsionou o desenvolvimento do Direito Sanitário em nosso País, cujas fontes são, hoje, uma importante produção normativa voltada para o tratamento jurídico da questão da saúde no Brasil, desencadeada pela Constituição de 1988.

\section{Referências}

\section{Textos constitucionais}

Carta da Lei de 25 de março de 1824. In: NOGUEIRA, Octaviano. Constituições Brasileiras: 1824. Brasília: Senado Federal e Ministério da Ciência e Tecnologia, Centro de Estudos Estratégicos, 2001. (Coleção, Constituições Brasileiras: v. 1). [s/ ISBN]

Constituição da República dos Estados Unidos do Brasil, de 24 de fevereiro de 1891. In: BALEEIRO, Aliomar. Constituições Brasileiras: 1891. Brasília: Senado Federal e Ministério da Ciência e Tecnologia, Centro de Estudos Estratégicos, 2001. (Coleção, Constituições Brasileiras: v. 2). [s/ ISBN]

Constituição da República dos Estados Unidos do Brasil, de 16 de julho de 1934. In: POLETTI, Ronaldo. Constituições Brasileiras: 1934. Brasília: Senado Federal, e Ministério da Ciência e Tecnologia, Centro de Estudos Estratégicos, 1999. (Coleção, Constituições Brasileiras: v. 3). [s/ ISBN]

Constituição dos Estados Unidos do Brasil, de 10 de novembro de 1937. In: COSTA PORTO, Walter. Constituições Brasileiras: 1937. Brasília: Senado Federal e Ministério da Ciência e Tecnologia, Centro de Estudos Estratégicos, 2001. (Coleção, Constituições Brasileiras: v. 4). [s/ ISBN]

Constituição dos Estados Unidos do Brasil, de 18 de setembro de 1946. In: BALEEIRO, Aliomar; SOBRINHO, Barbosa Lima. Constituições Brasileiras: 1946. Brasília: Senado Federal e Ministério da Ciência e Tecnologia, Centro de Estudos Estratégicos, 2001. (Coleção, Constituições Brasileiras: v. 5). [s/ ISBN]

Constituição da República Federativa do Brasil, de 24 de janeiro de 1967. In: CAVALCANTI, Themístocles Brandão; BRITO, Luiz Navarro de; BALEEIRO, Aliomar. Constituições Brasileiras: 1967. Brasília: Senado Federal e Ministério da Ciência e Tecnologia, Centro de Estudos Estratégicos, 2001. (Coleção, Constituições Brasileiras: v. 6). [s/ ISBN]

Emendas Constitucionais. In: Constituições Brasileiras: 1969. Brasília: Senado Federal e Ministério da Ciência e Tecnologia, Centro de Estudos Estratégicos, 1999. (Coleção, Constituições Brasileiras: v. 6a). [s/ ISBN]

Constituição da República Federativa do Brasil, de 5 de outubro de 1988. In: TÁCITO, Caio. Constituições Brasileiras: 1988. Brasília: Senado Federal e Ministério da 
Ciência e Tecnologia, Centro de Estudos Estratégicos, 2001. (Coleção, Constituições Brasileiras: v. 7). [s/ ISBN]

\section{Referências bibliográficas}

AITH, Fernando. Curso de Direito Sanitário - a proteção do direito à saúde no Brasil. São Paulo: Quartier Latin, 2007. ISBN 85-7674-262-4.

BONAVIDES, Paulo; ANDRADE, Paes de. História Constitucional do Brasil. Rio de Janeiro: Paz e Terra, 1991. ISBN 9788587260390.

BORJA, Célio. Brasil. In: FUENZALIDA-PUELMA, Hernán L.; CONNOR, Susan S. El derecho a la salud en las Americas. Estudio constitucional comparado. Washington: Organização Panamericana da Saúde, 1989. p. 110-126. ISBN 9275115095.

CAMPOS, Gastão Wagner de Souza. Modo de co-produção singular do Sistema Único de Saúde: impasses e perspectivas. Saúde em Debate, 33(81): 47-55, jan./abr. 2009. ISSN 01103-1104.

CHALHOUB, Sidney. Cidade Febril. Cortiços e epidemias na Corte Imperial. São Paulo: Companhia das Letras, 1996. ISBN 85-7164-587-6.

CONILL, Eleonor Minho. Epidemiologia e Sistemas de Saúde. In: MINISTÉRIO DA SAÚDE. Direito Sanitário e Saúde Pública (v. 1) (Série Legislação de Saúde), Brasília, 2003. p. 207-224. ISBN 85-334-0733-5.

CUNHA, Paulo Ferreira. Raízes da República. Introdução Histórica ao Direito Constitucional. Coimbra: Almedina, 2006. ISBN 9789724016801.

DALLARI, Sueli Gandolfi. A construção do direito à saúde no Brasil. Revista de Direito Sanitário, 9(3):5-6, nov. 2008/fev. 2009. ISSN 1516417-9.

DELDUQUE, Maria Célia; OLIVEIRA, Mariana Siqueira de Carvalho. Tijolo por tijolo: a construção permanente do direito à saúde. In: COSTA, Alexandre Bernardino et al. (org.) O Direito achado na rua : introdução crítica ao direito à saúde. Brasília: CEAD/UnB, 2008. ISBN 978-85-7804-025-3.

DELDUQUE, Maria Célia; MARQUES, Sílvia Badim; ROMERO, Luiz Carlos. A saúde precisa de juízes epidemiologistas. Saúde em Debate, 33(81): 80-87, jan./abr. 2009. ISSN 01103-1104.

FIGUEIREDO, Maria Betânia Gonçalves. A arte de curar: cirurgiões, médicos, boticários e curandeiros no século XIX em Minas Gerais. Belo Horizonte: Argvmentvm, 2008. ISBN 978-85-98885-32-2

FONSECA, Cristina M. Oliveira. Saúde no Governo Vargas (1930-1945): dualidade institucional de um bem público. Rio de Janeiro: Fiocruz, 2007. ISBN 978-85-7541132-2.

GERSCHMAN, Sílvia. A Democracia Inconclusa. Um estudo da Reforma Sanitária Brasileira. Rio de Janeiro: Fiocruz, 2004. ISBN 85-85676-20-5.

GOMES, Maria Angélica. Equidade e Universalidade do Direito à Saúde: representação de interesses no Congresso Nacional, 1987-1990. Dissertação (mestrado) - Faculdade de Estudos Sociais Aplicados, Universidade de Brasília, 1996. 
MACHADO, Roberto; LOUREIRO, Ângela; LUZ, Rogério; MURICY, Kátia. Danação da Norma: Medicina e Constituição da Psiquiatria no Brasil. Rio de Janeiro: Graal, 1978. [s/ ISBN]

MARQUES, Marília Bernardes. A reforma sanitária brasileira e a política científica e tecnológica necessária. Rio de Janeiro: Fiocruz, 1989. [s/ ISBN]

PAIM, Jairnilson Silva. Uma análise sobre o processo da reforma sanitária brasileira. Saúde em Debate, 33(81):27-37, jan./abr. 2009. ISSN 01103-1104.

ROEMER, Ruth. El derecho a la atención de la salud. In: FUENZALIDA-PUELMA, Hérman L.; CONNOR, Susan Scholle (ed.) El derecho a la salud en las Americas. Estudio constitucional comparado. Washington: Organização Panamericana da Saúde, 1989. ISBN 9275115095.

ROMERO, Luiz Carlos P. O Sistema Único de Saúde - um capítulo a parte. In: DANTAS, Bruno et al. (org.) Os cidadãos na Carta Cidadã. Brasília: Senado Federal, Instituto Legislativo Brasileiro, 2008. v. 5, p. 67-88. ISBN 978-8587499-08-0.

SANTOS, Nelson Rodrigues dos. A Reforma Sanitária e o Sistema Único de Saúde: tendências e desafios após 20 anos. Saúde em Debate, 33(81):13-26, jan./abr. 2009. ISSN 01103-1104.

SILVA, Sílvio Fernandes da. Sistema Único de Saúde 20 anos: avanços e dilemas de um processo em construção. Saúde em Debate, 33(81): 38-46, jan./abr. 2009. ISSN 01103-1104. 